\title{
Nonrenal Clearance
}

National Cancer Institute

\section{Source}

National Cancer Institute. Nonrenal Clearance. NCI Thesaurus. Code C102376.

A measurement of the total clearance rate of a substance from the blood minus the renal clearance rate of that substance. 